\title{
研究
}

\section{偏光解析法による薄膜の自動インライン評価 ${ }^{*}$}

\author{
林康明** . 松沢 昭生*** ・福留 理一**** \\ (昭和 56 年11月 4 日 受理)
}

\begin{abstract}
Automatic In-line Evaluation of Thin Films with Ellipsometry
Yasuaki HAYASHI, Akio MATSUZAWA and Riichi FUKUTOME
\end{abstract}

(Institute for Super Materials, ULVAC CO., Sambu-cho, Chiba)

(Received November 4, 1981)

An ellipsometer is installed in an unloading chamber of in-line plasma CVD system to evaluate film thicknesses and refractive indices. The ellipsometer is a rotating-analyzer type, in which a $\lambda / 4$ compensator is always positioned with the fast axis $45^{\circ}$ setting a polarizer prism to a proper azimuth. The $\mathrm{SiN}_{\boldsymbol{x}}$ films on silicon substrates prepared by plasma CVD are automatically and successivley checked in the system.

\section{1. はじめに}

最近，各半導体メーカーは，半導体デバイスの製造ラ インにおいて, 省力化や, 製品の生産性, 信頼性の向上 をはかるため, 一連のプロセスを全て自動化していこう とする動きにある ${ }^{1 \sim 3)}$. ここにおいて, 制御を精密化す る上で，プロセスや膜の評価は重要な課題である，評価 の手法としては，プロセス中に評価するインプロセス評 価法と, プロセス処理後に行うインライン評価法があ る4). インプロセス評価法でモニターしながらプロセス を制御する方が, 精密な結果が得られる. しかし, ロッ ト毎のばらつきは条件の設定だけで押さえられ，一方， 処理機能が経時的に変動し, 継続性のある傾向を示す場 合はインライン評価法によってモニターし調整するだけ で充分であり，また，その方が技術的にも容易である.

ところで, 偏光解析法は, 従来, 半導体デバイス作成 ラインにおいて, 主に絶縁膜の膜厚や（光学的）膜質の 評価に利用されてきたが，製造ラインシステム内に組み 込まれるまでには至っていない，それは，装置が大がか りとなりシステム内への組み込みが困難なことや, 測定 やデータの解析に時間がかかることなどに原因してい る. 近年, 計算機を利用した回転検光子型偏光解析装

* 昭和56年 3 月 30 日 第28回応用物理学関係連合講演会にて講演

** 日本真空技術(株)超材料研究所 (千葉県山武町)

*** 同上 (現在, 日本真空技術(株) 第三事業部)

**** 同上 (現在, タイゴールド(株))
置 $^{5 \sim 7)}$ が開発されて，測定が速くなり，構成も簡単にな ってきた. 本研究では, 従来の回転検光子型偏光解析装 置を, さらに構造, 測定方法, 解析方法において改良を 行い, この装置をインラインシステムに組み込んで, 半 導体デバイスのパッシベーション膜作成プロセスのイン ライン評価への応用について検討を行った.

\section{2. 偏光解析装置}

\section{1 測定方法の改良}

自動偏光解析装置は, これまで数種報告されている ${ }^{8,8)}$. この5ち, 構造の簡単さ, 測定時間の速さでは, 回転検光子型偏光解析装置が優れ, 工業用として適して いる.

回転検光子型偏光解析装置は, 一定の偏光状態にある 光を試料に入射し，検光子を回転しながら光電測光によ り反射光の偏光状態を測定する. 入射光と反射光の間の 偏光状態の変化は, 試料の表面状態に関する情報を含ん でいる，そこで，偏光の $p$ 成分（入射面に平行な成分） と $s$ 成分（大射面に垂直な成分）の振幅反射率の比を， $\tan \Psi$, 反射により生じる $p$ 成分と $s$ 成分の位相変化の差 を $\Delta$ とし, $\Psi, \Delta$ を偏光解析法において, 試料の表面状 態を表わすパラメータとしている，すなわち， $p$ 成分と $s$ 成分の複素振幅反射率

$$
\left\{\begin{array}{l}
\boldsymbol{r}_{p}=r_{p} \cdot \exp \left(i \Delta_{p}\right) \\
\boldsymbol{r}_{s}=r_{s} \cdot \exp \left(i \Delta_{s}\right)
\end{array}\right.
$$

の比は次式により表わされる. 


$$
\begin{aligned}
\frac{\boldsymbol{r}_{p}}{\boldsymbol{r}_{s}} & =\frac{r_{p}}{r_{s}} \exp \left\{i\left(\Delta_{p}-\Delta_{s}\right)\right\} \\
& =\tan \Psi \cdot \exp (i \Delta)
\end{aligned}
$$

試料が固体表面上の薄膜であれば，その光学定数と膜厚 は, これらのパラメータ $\Psi, \Delta$ と一定の関係で結ばれて おり, 計算により求められる。

通常, 回転検光子型偏光解析装置に抒いて, 入射光 は, $p$ 成分と $s$ 成分の振幅が等しく互いの位相差が $0^{\circ}$, すなわち, 入射面より $45^{\circ}$ 方向に傾いた直線偏光に設定 する (Fig. 1 (a)). 入射光が直線偏光の場合, パラメータ $\Delta$ は反射偏光の $p$ 成分と $s$ 成分の位相差をそのまま表わ すことになるため, 試料の表面状態が, $\Delta=0^{\circ}$ 又は $180^{\circ}$ に対応しているとき, 反射光は直線偏光になる（すなわ ち, $p$ 成分と $s$ 成分の位相差が $0^{\circ}$ 又は $\left.180^{\circ}\right)$. 回転検光 子型のよ5な測光型偏光解析装置の欠点は, 反射光が直 線偏光に近いと測定精度が悪くなり, また偏光の回転方 向（すなわち，位相差の正負）の判別が困難なところに ある.

そこで，パラメータ $\Delta$ が $0^{\circ}$ 又は $180^{\circ}$ に近いことがわ かっているときは, 入射光の $p$ 成分と $s$ 成分の位相差を $90^{\circ}$ にするために, $1 / 4$ 波長板を偏光子と試料の間に進相 軸を入射面より $0^{\circ}$ 方位に挿入して (Fig. 1(b)) 測定を行 5. この場合, 反射偏光は, $p$ 成分と $s$ 成分の位相差が $\Delta+90^{\circ}$ になり $, \Delta \cong 0,180^{\circ}$ では位相差は $90^{\circ},-90^{\circ}$ に 近い值をとり, 直線偏光の場合とは逆に, 精度良い測定 が可能で，偏光の回転方向の判別も容易である.

以上が, 従来の回転検光子型偏光解析装置による測定 法である.ここで, 最初にいずれかの手段で測定した結 果, 反射光に近いことがわかり, 他の手段により測定を もら一度行ら場合, $\lambda / 4$ 板の出し入れは, 従来, 手動で 行われており, これも含めて自動化しょらとすると, 偏 光解析装置はやや複雑になる. また, 測定に倍以上の時 間を要する.

本研究で目的としているのは，一定の条件で作成され た薄膜を, インライン方式により評価することである. 試料薄膜の膜厚, 光学定数は, 決められた值の近傍の一 定の範囲内にあると考えてよい. これに対応して，パラ メータ $\Delta$ むある值 $\Delta_{0}$ 前後の值をとる. そこで, $\Delta=\Delta_{0}$ で反射偏光の $p$ 成分と $s$ 成分の位相差が $90^{\circ}$ (又は $-90^{\circ}$ ) となるように入射光の偏光状態を調整することができれ ば， $\Delta_{0}$ の周辺で精度のよい測定が可能となる。 また, 従来の方法に比較して, 反射光が直線偏光になるまでの $\Delta$ の変動についての範囲が広いため, 膜の膜厚, 光学定 数の変動が大きいところまで, 一回の測定で正しい值を 得ることができるようになる.

入射偏光の $p$ 成分と $s$ 成分の位相差を任意に調整でき
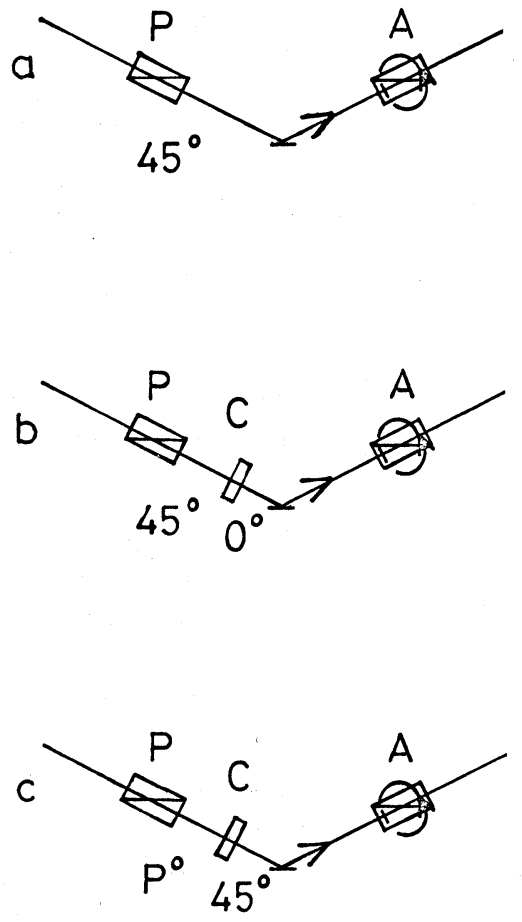

Fig. 1 Configurations of rotating-analyzer ellipsometer. P: polarizer, C: $\lambda / 4$ compensator, A: analyzer.

(a), (b) conventional way, (c) new way.

るようにするためには, 偏光子と試料との間に $1 / 4$ 波長 板を進相軸を入射面より $45^{\circ}$ 方位に保って常時㨂入して おき (Fig. 1(c))，偏光子の方位角 $P$ を任意に設定できる ようにすればよい，この場合，反射偏光の $p$ 成分と $s$ 成 分の位相差は, 後で示すように, $\Delta+2 P-90^{\circ}$ となるの で, 偏光子の方位角 $P$ を

$$
P=-\frac{\Delta_{0}}{2}
$$

に合わせておけば, 反射偏光 の位相差は, $\Delta-\Delta_{0}-90^{\circ}$ となり, $\Delta=\Delta_{0}$ の近傍では $-90^{\circ}$ に近く, 測定精度が 良く, 特性が基準よりはずれた膜を評価する場合でも, 反射偏光は直線偏光になりにくい.

上述の説明を数式を用いて厳密に示すと以下のように なる.

1/4波長板は，常に不完全さによる誤差を伴っている ため, この誤差も考慮に入れて, 検光子に入ってくる反 射光の偏光状態を求めてみる. 反射光の $p$ 成分, $s$ 成分 の複素振幅をそれぞれ， $\boldsymbol{E}_{p}, \boldsymbol{E}_{s}$ とすると, Jones 行列 ${ }^{10)}$ を用いて，

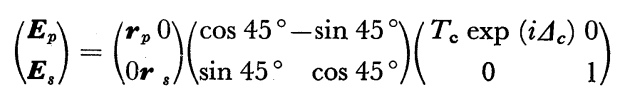




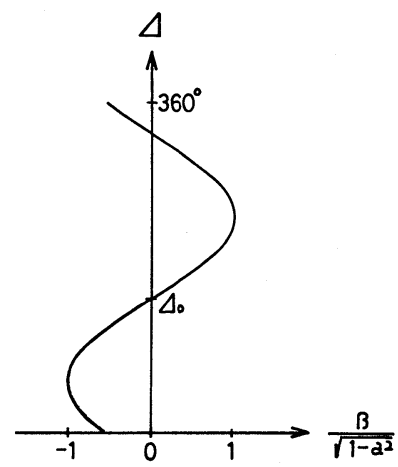

Fig. 2 Relation between $\Delta$ and $\beta / \sqrt{1-\alpha^{2}}$.

$$
\times\left(\begin{array}{rr}
\cos 45^{\circ} & \sin 45^{\circ} \\
-\sin 45^{\circ} & \cos 45^{\circ}
\end{array}\right)\left(\begin{array}{l}
\cos P \\
\sin P
\end{array}\right)
$$

となる．但し， $\boldsymbol{r}_{p}, \boldsymbol{r}_{s}$ は(1)式の定義のとおり， $T_{c}, \Delta_{c}$ は それぞれ $1 / 4$ 波長板の進相軸と遅相軸の間の振幅透過率 比と，位相差を表わし， $P$ は偏光子の方位角である.さ らに, 回転検光子の方位角を $A$ とすると, 光検出器に達 する光の強度 $I$ は

$$
\begin{aligned}
I & =I_{0}\left|(\cos A \sin A) \cdot\left(\begin{array}{l}
\boldsymbol{E}_{p} \\
\boldsymbol{E}_{s}
\end{array}\right)\right|^{2} \\
& =I_{1}(1+\alpha \cos 2 A+\beta \sin 2 A)
\end{aligned}
$$

となる．ここで，I, $I_{1}$ は $A$ に無関係な定数で， $\alpha, \beta$ は， 偏光解析パラメータ $\Psi, \Delta$ と次のような関係にある.

$$
\left\{\begin{array}{l}
\tan \Psi=\sqrt{\frac{b}{a}} \cdot \sqrt{\frac{1+\alpha}{1-\alpha}} \\
\cos (\Delta+\delta)=\sqrt{\frac{a b}{c_{1}^{2}+c_{2}{ }^{2}}} \cdot \frac{\beta}{\sqrt{1-\alpha^{2}}}
\end{array}\right.
$$

但し, $a, b, c_{1}, c_{2}, \delta$ は定数で

$$
\left\{\begin{array}{l}
a=T_{c}{ }^{2}+1+\left(T_{c}{ }^{2}-1\right) \sin 2 P+2 T_{c} \cos \Delta_{c} \cos 2 P \\
b=T_{c}{ }^{2}+1+\left(T_{c}{ }^{2}-1\right) \sin 2 P-2 T_{c} \cos \Delta_{c} \cos 2 P \\
c_{1}=T_{c}{ }^{2}-1+\left(T_{c}{ }^{2}+1\right) \sin 2 P \\
c_{2}=2 T_{c} \sin \Delta_{c} \cos 2 P \\
\delta=\cos ^{-1} \frac{c_{1}}{\sqrt{c_{1}{ }^{2}+c_{2}^{2}}}=\sin ^{-1} \frac{-c_{2}}{\sqrt{c_{1}^{2}+c_{2}}}
\end{array}\right.
$$

である。

$\alpha, \beta$ の値は，検光子を回転し，その回転角 $A$ について 光強度 $I$ をフーリエ変換すれば，(5)式との対応からから 求めることができる. これから，(6)式を用いて偏光解析 パラメータ $\Psi, \Delta$ が求められる.

1/4波長板の誤差を考慮に入れないときは,

$$
\left\{\begin{array}{l}
T_{c}=1 \\
\Delta_{c}=90^{\circ}
\end{array}\right.
$$

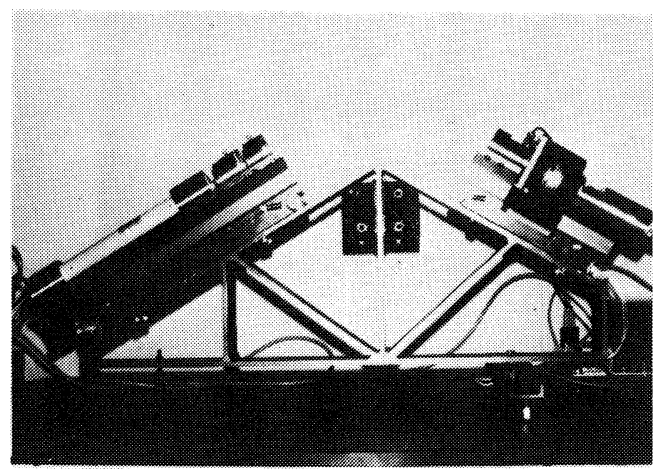

Fig. 3 Photograph of rotating-analyzer ellipsometer. Left: polarizer block, right: analyzer block.

$$
\left\{\begin{array}{l}
\tan \Psi=\sqrt{\frac{1+\alpha}{1-\alpha}} \\
\cos \left(\Delta+2 P-90^{\circ}\right)=\frac{\beta}{\sqrt{1-\alpha^{2}}}
\end{array}\right.
$$

となる。したがって，P=- $P$ / $/ 2$ であれば，(9)式の $\Delta$ に関する式は,

$$
\Delta-\Delta_{0}-90^{\circ}=\cos ^{-1}\left(\frac{\beta}{\sqrt{1-\alpha^{2}}}\right)
$$

となり， $\Delta$ は, $\Delta_{0}-90^{\circ}$ から $\Delta_{0}+90^{\circ}$ の範囲においては 一価関数であり,曲線の傾斜も小さくなる (Fig. 2). これ は，前述した 反射偏光の $p$ 成分と $s$ 成分の位相差が $90^{\circ}$

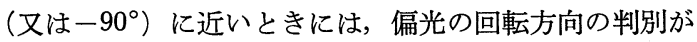
容易で，測定精度が良いことに対応している.

\section{2 偏光解析装置の概要}

Fig. 3 は，インライン評価用に試作した偏光解析装置 である。

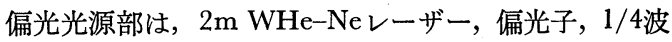
長板より構成されている.

検光受光部は, 検光子, パルスモーター，マグネティ ックスイッチ, 光検出器より成り, 従来のもの ${ }^{5 \sim 7)}$ より 簡易化されている. 検光子は，パルスモーターにより， 直接ドライブされる. パルスモーターの軸には, 直径 5 $\mathrm{mm}$ の穴が軸方向にあけてあり, 検光子を通った光は, この穴を通り抜け受光器に達する. パルスモーターは $1.8^{\circ}$ 刻みにステップ回転し，一秒間に全周 200 点におけ る光量が，ディジタル信号となって計算機へ入力され る. マグネティックスイッチからは，一回転毎に一ケの パルス信号が出され，検光子の回転基準点を決めてい る.

計算機には, あらかじめ, 入射角, 基板の光学定数, 偏光子の方位角 $P$ や， $1 / 4$ 波長板の $T_{c}, \Delta_{c}$ などを入力 し，(7)式の定数なども求めておく．外部からデータが取 


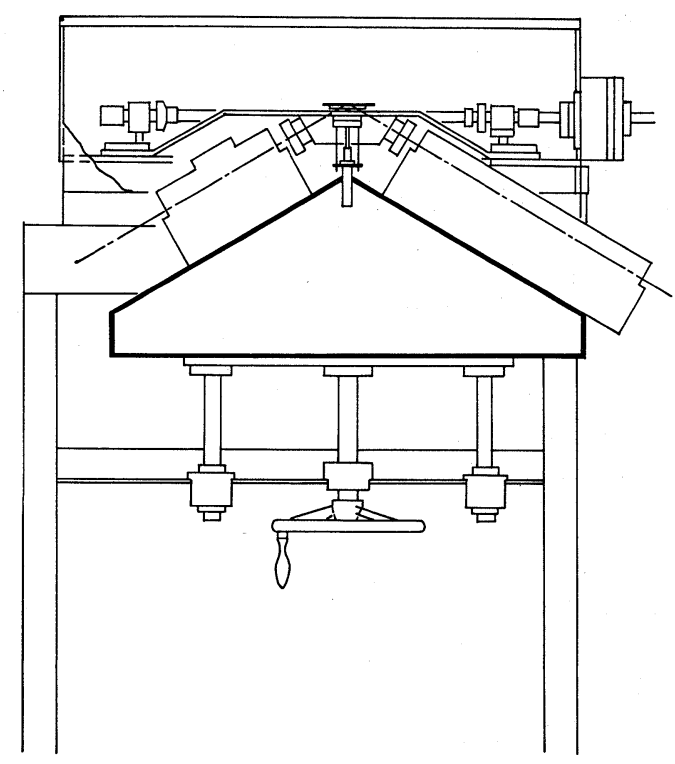

Fig. 4 Cross-sectional view of ellipsometer settled in in-line plasma CVD system.

り込まれると計算を開始し，パラメータ $\Psi, \Delta$ および膜 厚，屈折率をアウトプットするようになっている，パラ メータ $\Psi, \Delta$ から膜厚, 屈折率を求める計算は, 二変数 の Newton-Raphson 法を用いて行っている. 計算機に は，パナファコム C $15 \mathrm{E}$ パーソナルコンピュータを利用 し, 膜厚, 屈折率を求めるまでに約 5 秒を要する.

\section{3. 偏光解析法による $\operatorname{SiN}_{\mathrm{X}}$ 膜のインライン 評価}

\section{1 偏光解析装置のインラインシステムへの組み込 み}

偏光解析装置を，インラインプラズマ CVD 装置 ${ }^{11)} の$ 取出側中間室下部に組み込んだ例を Fig. 4 に示す。 反 応室より送り出されたウェハートレイは，ここで一旦停 止する，トレイは，反応室内での熱によりかなりひずみ を生じているため, 測定前にウェハーホルダーによりウ エハーをトレイより少しく持ち上げて，一定の傾き，高 さに固定する. 次に, 偏光解析装置のコントロール部へ スタートの信号が送りこまれ，測定が開始されるように なっている.

インラインプラズマ CVD 装置は，排気系にロータリ 一ポンプ 6 台, メカニカルブースターポンプ 3 台を用 い, プラズマ励起は，2〜3kW, $13.56 \mathrm{MHz}$ の RFによ って行われる. 測定に際しては, これらの機械的, 電気 的雑音の影響が問題となる。 そこで，これを調べるた め, トレイ搬送系以外をすべて稼動し，トレイを停止さ せたままで, 偏光解析装置により $\mathrm{Si}$ ウェハー上の $\mathrm{SiN}_{\mathbf{X}}$

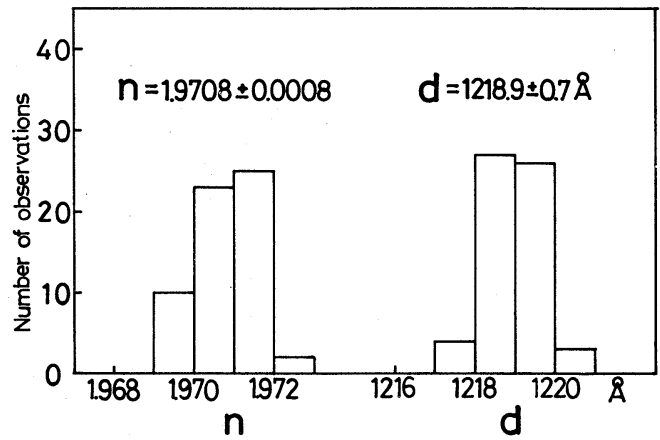

Fig. 5 Number distribution of observed values 'n' (refractive index) and 'd' (film thickness).

膜の同一点を60回測定し, 観測值のばらつきを求めた. その結果, $\Delta=255.92 \pm 0.03^{\circ}, \Psi=25.802 \pm 0.016^{\circ}$ を得, 測定上支障のないことを確認している. Fig. 5 は, これらのパラメータから計算された, $d$ (膜厚),$n$ (屈 折率) の度数分布を示す.

\section{$3.2 \operatorname{SiN}_{\mathrm{x}}$ 膜のインライン評価}

プラズマ CVD 法により作成された $\mathrm{SiN}_{\mathbf{x}}$ 膜は, IC の パッシベーション膜などとして有用であるが，長時間に わたって連続的に成膜していく場合, プラズマの状態や 処理機能が, 時間と共に変化して, 膜質や膜厚が変わっ ていく恐れがあり，これを厳密にチェックしていかなけ ればならない, そこで, 偏光解析装置を利用して, 反応 室内でプラズマ $\mathrm{CVD}$ 法により作成された $\mathrm{Si}$ 上 $\mathrm{SiN}_{\mathbf{x}}$ 膜 の自動インライン評価の試験を行った. Fig. 6 は, この ようにして各トレイ毎に自動的に評価を行った結果の一 例である. このときの反応の条件は, 窒素をベースにし た 4 \% シランガスを用い, 圧力 $23.3 \mathrm{~Pa}, \mathrm{RF}$ パワー 1.8 $\mathrm{kW}$, 基板温度 $350^{\circ} \mathrm{C}$ 亿設定した. また, 偏光解析装置の 偏光光源部には， $1 / 4$ 波長板を進相軸を $45^{\circ}$ 方位にして挿 入し, 偏光子は, あらかじめ予想される膜厚, 屈折率から の計算により, $25^{\circ}$ 方位に設定している（この場合， $\Delta_{\mathbf{0}}$ $\left.310^{\circ}\right)$. この測定法によれば, 今回の例の場合, 従 来の 一回限りの測定と比べて， $\Delta$ 亿関して解析上の誤りをも たらすことはない.

\section{4. おわりに}

半導体デバイスのウェハー処理プロセスの評価法のう ち, インライン評価法について検討を行った. インライ ン評価法は, それほど厳密な要求はないが, 長時間, 連 続的に行うプロセスの経時的変動を調整しなければなら ない場合に適している。しかし, 集積回路のダート絶縁 膜, 層間絶縁膜の形成やエッチングプロセス等において は, 膜質, 膜厚のきわめて精密な制御が要求され, イン 

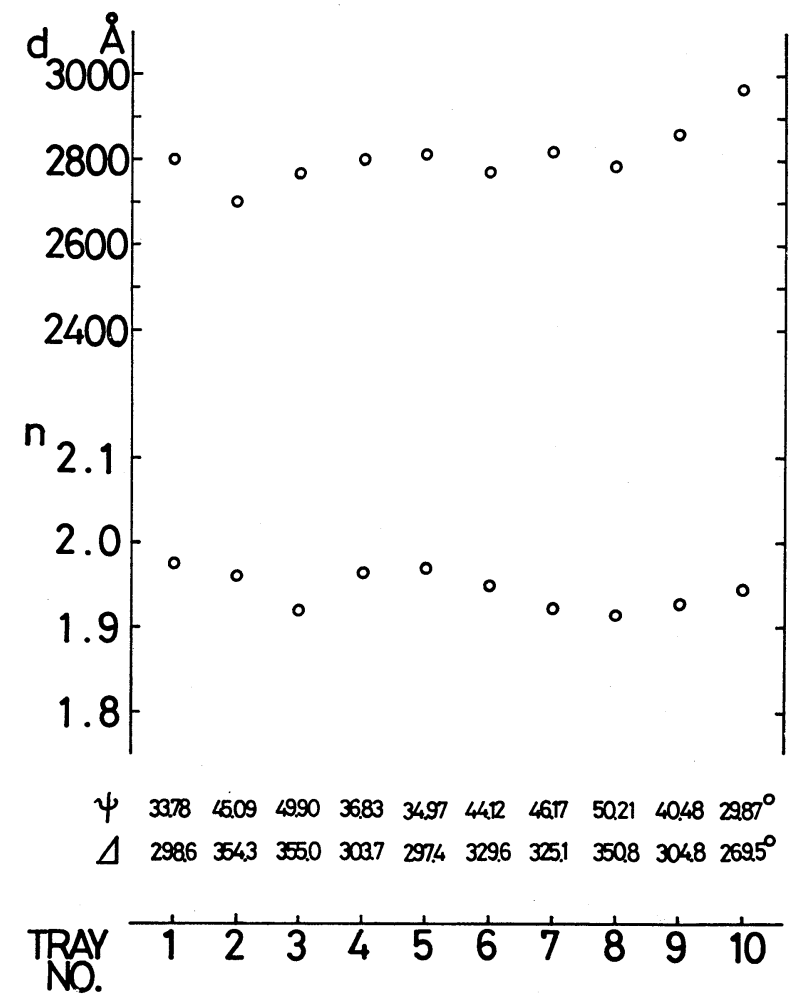

Fig. 6 Result of successive evaluation of $\mathrm{SiN}_{x}$ films formed in in-line plasma CVD system with ellipsometric monitor.

プロセス評価が必要である。偏光解析法は，膜厚や膜質 の精確な測定ができるため，インプロセス評価用のモニ ターとしても簡単に利用できるようになれば, 半導体デ バイスの高集積化, 品質向上の上で, 一役を荷うことに なるであろう。

\section{謝 辞}

本稿を書くに当たって貴重なご助言をお寄せ下さった 超材料研究所の伊藤昭夫所長に心より感謝の意を表した い.

\section{[文献]}

i）「拍車がかかる LSI 製造ラインの連続自動化」 : 日経エレクトロニクス, 3 月31日号 (1980) 54.

2) 原田宙幸 : 電子通信学会誌 64 (1981) 980 .
3) 古口栄男, 米沢敏夫, 硲野重喜 : 電子材料 11 月号 (1979) 29.

4) 松川隆行, 河津 哲：電子材料 11月号 (1980) 30 .

5) P. S. Hauge and F. H. Dill: IBM J. Res. Devel. 17 (1973) 472.

6) H. H. Bloem, W. E. Goetz, R. N. Jackson and R. W. Kern: Electro-Optical Systems Design March (1980) 38.

7) D. E. Aspnes and A. A. Studna: Appl. Opt. 14 (1975) 220.

8) R. H. Muller: Surface Sci. 56 (1976) 19.

9) D. E. Aspnes, in B. O. Seraphin (ed.): Optical Properties of Solids (North Holland Publ. Co., Amsterdam, 1975) p. 799.

10) R. C. Jones: J. Opt. Soc. Am. 31 (1941) 488.

11）松沢昭生, 伊藤隆生, 石川裕一, 柳田博司 : 真 空 23 (1980) 199. 